\title{
Revealing Cropland Abandonment and Food Insecurity in War-ravaged South Sudan
}

\section{Victor Olsen ( $\nabla$ victor.olsen@hotmail.com )}

University of Copenhagen

\section{Rasmus Fensholt}

University of Copenhagen

\section{Rogerio Bonifacio}

United Nations World Food Programme

\section{Van Butsic}

Berkeley University of California

\section{Deepak Ray}

University of Minnesota

\section{Alexander Prishchepov}

University of Copenhagen https://orcid.org/0000-0003-2375-1651

\section{Article}

Keywords: Armed Conflicts, Targeted Relief Distribution, Satellite Remote Sensing

Posted Date: October 20th, 2020

DOl: https://doi.org/10.21203/rs.3.rs-89883/v1

License: (c) (i) This work is licensed under a Creative Commons Attribution 4.0 International License. Read Full License

Version of Record: A version of this preprint was published at Nature Food on December 16th, 2021. See the published version at https://doi.org/10.1038/s43016-021-00417-3. 


\section{Revealing Cropland Abandonment and Food Insecurity in War-ravaged South Sudan}

4 Victor Mackenhauer Olsen ${ }^{1 *}$, Rasmus Fensholt ${ }^{1}$, Rogerio Bonifacio ${ }^{2}$, Van Butsic ${ }^{3}$, Deepak Ray ${ }^{4}$, Alexander V. Prishchepov ${ }^{1}$

6

$8{ }^{1}$ Department of Geosciences and Natural Resource Management (IGN), University of Copenhagen, Øster

$9 \quad$ Voldgade 10, DK-1350 København K, Denmark

$10 \quad{ }^{2}$ Vulnerability Analysis and Mapping (VAM), United Nations World Food Programme (WFP), Via

11 Cesare Giulio Viola, 68, 00148 Roma RM, Italy

$12{ }^{3}$ Department of Environmental Science, Policy, \& Management, Berkeley University of California, 130

13 Mulford Hall 3114, CA 94720, Berkeley, United States of America

$14{ }^{4}$ Institute on the Environment (IonE), University of Minnesota, 1954 Buford Ave

15 St. Paul, MN 55108, Minnesota, United States of America

16

17

$18 *$ corresponding author:

19 Victor Mackenhauer Olsen

20 victor.olsen@hotmail.com

$21+4560125782$

22

23 


\section{Abstract}

26 Armed conflicts often result in cropland abandonment with significant impacts on food security.

27 Moreover, conflicts restrict the collection of on-the-ground information required for organizing

28 targeted relief distribution. Satellite remote sensing provides a way of observationally gathering

29 information about disruptions during armed conflicts and food-security status in conflict zones.

30 Using $~ 7500$ multisource satellite images, we implemented a data-driven approach that showed a

31 reduction in cultivated croplands in war-ravaged South Sudan by 23\% from 2016 to 2018.

32 Propensity score matching revealed a close relationship between cropland abandonment and

33 armed conflicts that lead to drastic decreases in the available food supply. If war-induced

34 abandonment had not occurred, our analysis shows that the abandoned croplands could have

35 supported at least a quarter of the population in the southern states of South Sudan. Here, we

36 demonstrate that remote-sensing technology can play a crucial role in rapid assessments of

37 cropland abandonment in food-insecure regions, thus improving the basis for timely aid

38 provision.

39

40

41

42 


\section{Introduction}

44 Food insecurity remains a prevalent problem around the world ${ }^{1,2}$. Approximately 821 million 45 people were facing food insecurity in 2017, of whom 124 million had an acute need of food ${ }^{3}$.

46 Food insecurity signifies a lack of access to sufficient nutrients essential to support life and

47 ranges from nutritional deficiency to famine ${ }^{3}$. With economic and technological developments,

48 the relative number of people facing food insecurity has declined significantly over the $20^{\text {th }}$

49 century. However, the absolute number of food-insecure people has remained high over the past

50 decades and has even increased over the last three years, in part due to climate change and

51 violent conflict ${ }^{3}$. The importance of addressing food insecurity is articulated in the United

52 Nations's second sustainable development goal, which aims at ending hunger by $2030^{4}$.

53 However, to reverse the current trend and fulfill the purpose of eradicating hunger, more timely

54 and accurate information on food production, food availability, and land use is needed.

55 Food insecurity is closely linked with armed conflict and land abandonment. Armed conflicts are

56 among the major drivers of cropland abandonment ${ }^{5-7}$, which may have multiple implications for

57 the environment ${ }^{8}$ and may serve as a proximate cause of food insecurity ${ }^{5,6}$. In 2019 , all 19

58 countries suffering from protracted food crises were also affected by armed conflicts ${ }^{9,10}$.

59 Understanding the impacts of armed conflict on cropland abandonment is, therefore, important

60 for addressing the root causes of food insecurity. To achieve this, and to provide timely and

61 accurate information on food production, better means of agricultural assessments are needed, as

62 field surveys are often restricted due to safety concerns and inaccessibility. Earth observation

63 techniques have potential as a means of extracting agricultural information and better

64 understanding the drivers of food insecurity. 
65 The challenge of food insecurity and adequate aid provision is particularly pressing in South

66 Sudan. The country has suffered from several years of violent conflict, which has disrupted

67 agricultural production, resulting in cropland abandonment and restricted access to markets ${ }^{9}$.

68 Ultimately, the conflicts in South Sudan resulted in nationwide food insecurity and periodic

69 famine ${ }^{11}$. In South Sudan, a large proportion of the population relies on local markets and

70 smallholder farming to meet their nutritional needs, making them vulnerable to local fluctuations

71 in food availability ${ }^{11,12}$. The conflict restricted access for agricultural surveyors and resulted in

72 limited information on agricultural production in the region, which is necessary to inform

73 humanitarian response ${ }^{11}$. Here, we used a fusion of open-access multisource high-resolution data

74 from the ESA Copernicus and USGS satellite systems to gather information about the state of

75 agricultural production in South Sudan in relation to conflicts.

76 We mapped cropland in three states of South Sudan: Western Equatoria, Central Equatoria, and

77 Lakes, from 2016 to 2018. We used multisource satellite imagery, data fusion, and machine-

78 learning supervised image classification techniques. Agriculture in South Sudan is characterized

79 by smallholder farming and small agricultural plots. To detect cropland, we took advantage of

80 the improved spatial resolution (as high as 10 meters for some bands) of freely accessible optical

81 Sentinel-2 and radar Sentinel-1 images. Sentinel data were combined with 30-m Landsat-8 and

82 250-m Aqua/Terra MODIS products to fill cloud-induced gaps in monthly image composites.

83 Finally, land cover was classified using the random forest classifier trained on an extensive in

84 situ dataset collected by the UN World Food Programme (WFP) during several field campaigns

85 and augmented with observations from very-high-resolution (VHR) commercial imagery

86 available from PlanetScope $\mathrm{TM}^{\mathrm{TM}}$ and GoogleEarth ${ }^{\mathrm{TM}}$. 
87 We statistically compared the extent of cropland in conflict and non-conflict areas to assess the conflict's impact during 2017 and 2018. To attribute the abandonment patterns to the ongoing

89 conflicts, we conducted a comparative analysis of cropland abandonment in conflict and non-

90 conflict areas and reduced confounder bias using propensity score matching ${ }^{13,14}$. Propensity

91 score matching reduces bias in the comparative analysis by subsampling (or "matching") the data

92 set to only include samples comparable to the causal variable under investigation ${ }^{15}$. By matching

93 samples on the likelihood of conflict, based on the distance to roads, distance to settlements, and

94 county-level population density, we satisfied the conditional independence assumption and

95 compared cropland abandonment in the two groups to assess the impact of conflict on cropland

96 abandonment.

97 Finally, we demonstrate the impact of war-induced cropland abandonment on kilocalorie

98 availability. Unattained cropland yields were measured using the mapped abandonment extent in

992017 and 2018 and the proportions and average yields of the major crops reported at the

100 provincial and state level. To convert the unattained crop yields into kilocalories, we used

101 extensive nutrient profile data on various crops from the Food Data Central of the U.S.

102 Department of Agriculture (USDA) ${ }^{16}$. 


\section{Results}

\section{Cropland Dynamic in South Sudan for 2016-2018}

109 Land-cover maps produced with combined multisource satellite data at 10-meter resolution

110 (Figure 1) reached overall accuracies of between 0.81 and 0.90 (Table 2) and revealed significant

111 cropland abandonment from 2016 to 2018 (Table 1). From 2016 to 2017, croplands declined by

$11210 \%$, with a net loss of approximately 39,000 ha. From 2017 to 2018 , cropland declined by

113 another $14 \%$, with a net loss of approximately 49,000 ha. In total, from 2016 to 2018, croplands

114 declined by approximately $23 \%$, from 390,000 hectares of active croplands in 2016 to 302,000

115 hectares in 2018. Cropland abandonment primarily occurred in Western Equatoria and Central

116 Equatoria states, whereas the Lakes state underwent an overall cropland increase from 2016 to 1172018. 

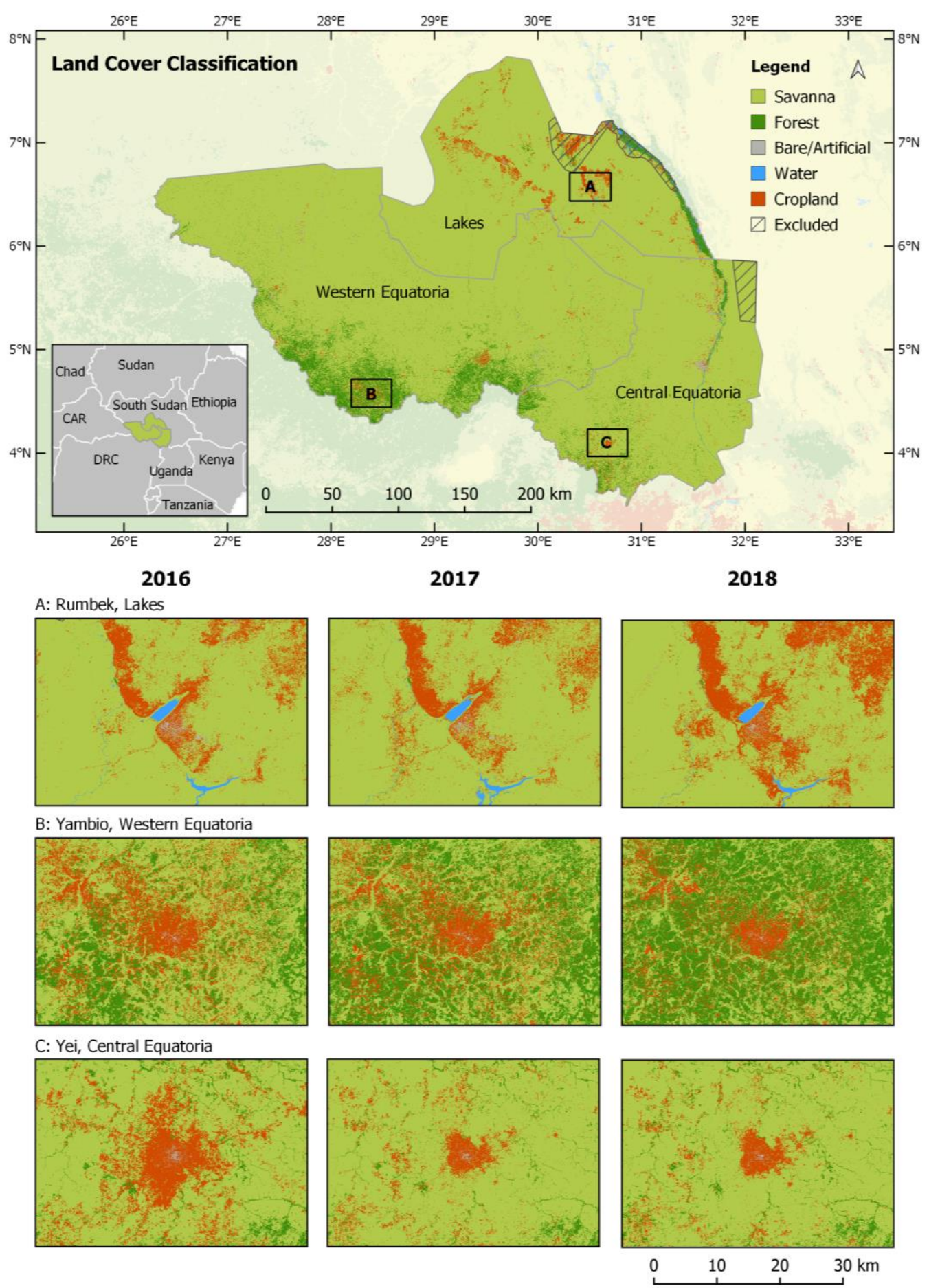

119 Figure 1. Land-cover map for 2018 produced with supervised image classification and the 120 examples of land-cover changes in three agricultural areas-Rumbek, Yambio, and Yei (A, 121 B, and C, respectively). 
123 Table 1. Non-error adjusted cropland extent (thousand ha).

\begin{tabular}{|c|c|c|c|c|}
\hline & \multicolumn{3}{|c|}{ Cropland extent } & Change $^{4}$ \\
\hline State & 2016 & 2017 & 2018 & 2016-2018 \\
\hline Western Equatoria & 92 & 90 & 68 & $-24 \quad 125$ \\
\hline Central Equatoria & 165 & 88 & 66 & -99 \\
\hline Lakes & 133 & 173 & 167 & $+34 \quad 126$ \\
\hline Total & 390 & 351 & 302 & -88 \\
\hline
\end{tabular}

128 Table 2. Accuracy assessment results.

\begin{tabular}{rrrrrr}
\hline & Savanna & Forest & Bare & Water & Cropland \\
\hline $\mathbf{2 0 1 6}$ & & & & & \\
Producer's Accuracy & 0.79 & 0.85 & 0.73 & 0.95 & 0.87 \\
User's Accuracy & 0.89 & 0.9 & 0.97 & 0.9 & 0.59 \\
Overall Accuracy & 0.81 & & & & \\
$\mathbf{2 0 1 7}$ & & & & & \\
Producer's Accuracy & 0.71 & 0.94 & 0.63 & 1 & 0.92 \\
User's Accuracy & 0.91 & 0.82 & 0.96 & 0.95 & 0.65 \\
Overall Accuracy & 0.8 & & & & \\
$\mathbf{2 0 1 8}$ & & & & & \\
Producer's Accuracy & 0.98 & 0.69 & 0.17 & 0.63 & 0.22 \\
User's Accuracy & 0.92 & 0.77 & 0.92 & 0.94 & 0.66 \\
Overall Accuracy & 0.9 & & & & \\
\hline
\end{tabular}

129

130 Note: These are non-adjusted classification accuracies. Details on accuracy assessment can be

131 found in the Methods section.

\section{Impact of Armed Conflict on Cropland Abandonment}

133 The comparative analysis with propensity score matching revealed a significantly larger

134 reduction of cropland extent between 2016 and 2018 in proximity to locations of violent conflicts

135 (Table 3). Within a 5-km radius around conflict and non-conflict locations, the average annual 
136 decline in cropland extent was -346 ha (-27.7\%) for the conflict group (out of an average

137 cropland extent of 1276 ha) and -79 ha for the non-conflict group (out of an average cropland

138 extent of $450 \mathrm{ha}$ ). This yielded a difference in mean decline of 266 ha. Similarly, at a 10-km

139 radius, the average annual decline in cropland extent was -488 ha $(-15.7 \%)$ for the conflict group

140 (out of an average cropland extent of 3,108 ha), and an increase of 46 ha $(+3.49 \%)$ for the non-

141 conflict (out of an average cropland extent of 1309 ha), yielding a difference in mean decline of -

142554 ha. Thereby, both the 5-km and 10-km buffer samples indicate a statistically significant

143 impact of conflict on the cropland abandonment.

144 Table 3. The average change of cropland extent in the conflict and non-conflict groups 145 between 2016 and 2018.

\begin{tabular}{|c|c|c|c|c|c|c|c|c|}
\hline \multirow[b]{2}{*}{ Sample } & \multicolumn{2}{|c|}{ Conflict zones } & \multicolumn{2}{|c|}{ Non-conflict zones } & \multirow[b]{2}{*}{$\begin{array}{l}\text { Diff. } \\
\text { (ha) }\end{array}$} & \multirow[b]{2}{*}{ T-Val. } & \multirow[b]{2}{*}{ DF } & \multirow[b]{2}{*}{ P-Val } \\
\hline & $\begin{array}{l}\text { Absolute } \\
\text { (ha) }\end{array}$ & $\begin{array}{l}\text { Relative } \\
(\%)\end{array}$ & $\begin{array}{l}\text { Absolute } \\
\text { (ha) }\end{array}$ & $\begin{array}{l}\text { Relative } \\
(\%)\end{array}$ & & & & \\
\hline $5 \mathrm{~km}$ & $\begin{array}{l}-345.5 \\
+/-68\end{array}$ & -27.1 & $\begin{array}{l}-79.5 \\
+/-35.3\end{array}$ & -17.7 & -266.1 & 3.47 & 145.78 & $6.84 \mathrm{E}-04$ \\
\hline $10 \mathrm{~km}$ & $\begin{array}{l}-487.9 \\
+/-145\end{array}$ & -15.7 & $\begin{array}{l}45.6 \\
+/-98\end{array}$ & 3.5 & -533.6 & 3.05 & 126.35 & $2.81 \mathrm{E}-03$ \\
\hline
\end{tabular}

\section{Impact of cropland abandonment on kilocalorie availability}

148 Cropland abandonment significantly reduced food production and the local supply needed to 149 meet the population's required kilocalorie needs. If abandonment had not taken place, the 150 assessment of the proportion of major crops and yields before the abandonment revealed that an 151 additional 172,403 tonnes of various crops could have been produced in the 2016-2017 crop

152 calendar year (Figure 2). These crops included 16,700 tonnes of sorghum, 7600 tonnes of maize, 153 and 125,350 tonnes of cassava, representing the bulk of staple food in the studied region.

154 Similarly, if abandonment had not occurred in the 2017-2018 crop calendar year, an additional 
15512,644 tonnes of sorghum, 5,040 tonnes of maize, and 73,808 tonnes of cassava could have been 156 produced. Such production could have met the kilocalorie needs of approximately 54,150

157 households and 44,080 households in the 2016-2017 and 2017-2018 crop calendar years,

158 respectively. In sum, if abandonment had not occurred, crop production could have satisfied an

159 additional 382,800 people in 2016-2017 and 327,600 people in 2017-2018, representing a quarter 160 of the population.

161

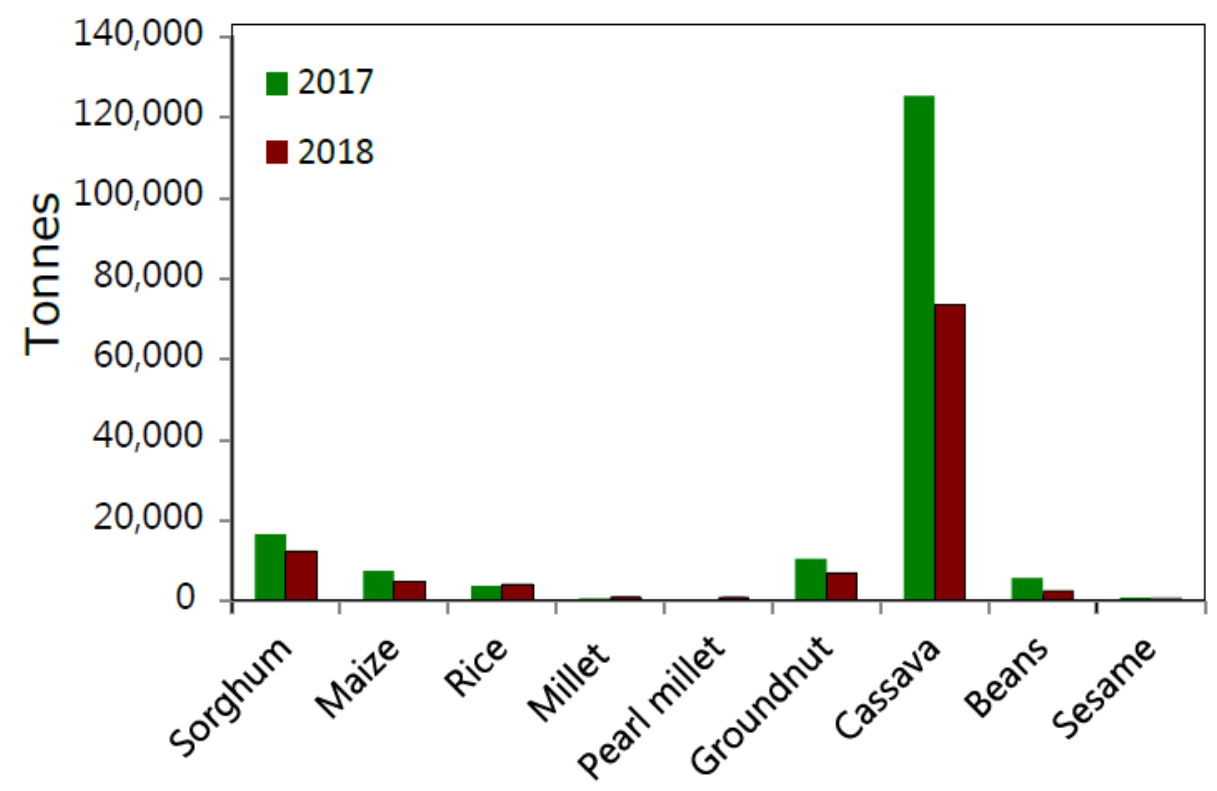




\section{Discussion}

166 Armed conflicts are trigger events that rapidly change land systems and often cause detrimental

167 short- and long-term impacts on food security ${ }^{6}$. Contemporary remote sensing systems provide

168 unprecedented technology to evaluate the implications of armed conflicts on food production

169 systems and can serve as an attractive complementary data source to conventional field-based

170 surveying methods. Based on a multisource satellite remote sensing imagery approach,

171 propensity score matching, and calculation of missed kilocalories, we unraveled how armed

172 conflict had a detrimental impact on South Sudan's food security. The results demonstrated the

173 crucial role of freely available satellite imagery, particularly the ESA Copernicus Sentinel-1 and

174 Sentinel-2 missions, for estimating agricultural production. The imagery was analyzed using a

175 multisource satellite fusion technique, implemented to limit clouds' impacts on optical satellite

176 data, to ultimately map smallholder farming at 10-meter spatial resolution. The demonstrated

177 utility of multisource image fusion techniques and the role of Sentinel-1 and Sentinel-2 data can

178 be relevant beyond South Sudan to many other parts of the world, where smallholder farming is

179 common, particularly in areas where armed conflicts occur ${ }^{17-20}$.

180 The analysis showed a statistically significant impact of conflict on cropland extent, which was

181 indicated by reduced areas under agriculture in proximity to armed conflict locations (both

182 within $5 \mathrm{~km}$ and $10 \mathrm{~km}$ buffer zones around the conflict locations) compared to non-conflict

183 areas, after accounting for the confounders. The observed cropland abandonment dramatically

184 limited the potential for local food production. Given the reliance on subsistence smallholder

185 farming and local markets, it resulted in unattained kilocalories and increased food insecurity.

186 Additionally, some local markets ceased to operate and, therefore, abandonment resulted in a

187 strong need for farming and non-farming groups to rely explicitly on food aid ${ }^{21}$. As quantified in 
188 our analysis, at least one-quarter of the population in Western Equatoria, Central Equatoria, and 189 Lakes could have been supported by the agricultural production of abandoned cropland, thus 190 highlighting the impact of conflict on food security.

191 Our findings on cropland abandonment and its implications for food security are worrying. By 192 the end of 2018, approximately $74 \%$ of the South Sudan population was estimated to be suffering 193 from food insecurity at the post-harvest time, and $26 \%$ of the population was severely food 194 insecure ${ }^{21}$. However, FAO/WFP also revealed that the number of food-insecure people 195 decreased slightly compared to the beginning of 2018 , albeit primarily due to substantial 196 humanitarian assistance. Therefore, local food production and combatting the ongoing 197 abandonment of croplands are critical to alleviating a chronic demand for food aid, closure of 198 local markets, and the distortion of trade routes ${ }^{21}$.

199 Here, we also established a link between war-induced cropland abandonment and food 200 insecurity. With the expectation of adverse impacts of climate change in already food insecure 201 regions often found in the Global South ${ }^{22}$, more violent conflicts and temporary or permanent 202 cropland abandonment may occur ${ }^{23,24}$. Given already widespread cropland abandonment with 203 complex implications for the environment and food security ${ }^{8,25,26}$, we also recommend revisiting 204 global abandonment patterns from a food-security perspective, particularly in already food205 insecure regions of the world ${ }^{5,27,28}$. 


\section{Methods}

\section{Study Area}

This study focuses on three states in South Sudan, which are of high importance to national food security: Western Equatoria, Central Equatoria, and Lakes (Figure 1) ${ }^{11,21,29}$. Geographically, the study area encompasses the so-called "greenbelt", which is the most productive agricultural zone in South Sudan, stretching along the southern and western national border ${ }^{21}$. The greenbelt was a traditional net exporter of food until the escalation of the conflict ${ }^{21}$. The study covered two growing seasons, 2016-2017 and 2017-2018.

Cropland is predominantly managed by smallholder farming with an average cereal area per household ranging from 0.4 to 1.3 ha and with very limited mechanization and irrigation ${ }^{21}$. Animal traction is rarely used and the fields are cleared by human power ${ }^{21}$. The application of mineral fertilizers, pesticides, and herbicides is rare. Soil fertility is predominantly managed by shifting cultivation and dung from household animals or pastoralist herds ${ }^{21}$. These farming practices provide low yields and the crops are prone to the infestation of pests and droughts.

Several crops are grown in the study area. Cereals comprise most cultivated areas, with sorghum and maize being the most important cereals, followed by bulrush millet and finger millet ${ }^{21}$. Two types of sorghum are commonly cultivated, the short-season sorghum with a $<90$-day growing period, and the long-season sorghum with a $>220$-day growing period ${ }^{21}$. Maize is the second most common cereal in the greenbelt and is often cultivated twice per season on the same plot.

The most common non-cereal crops are groundnuts and cassava that together comprise up to half of all crops in the greenbelt. The growing season is 200-220 days in the study area which allows for two to three harvests annually ${ }^{21}$. 


\section{Acquisition and Processing of Satellite Imagery}

232 Imagery from Sentinel-1, Sentinel-2, Landsat-8, and MODIS, as well as a Copernicus land-cover

233 product, were combined and used for land-cover classification in Google Earth Engine (GEE) ${ }^{30}$.

234 From the optical sensors, the Red, Green, Blue, NIR, and SWIR 1 and 2 bands were used

235 (Supplementary Table 1 and 2). The optical datasets were processed and combined following

236 five steps: 1) cloud masking, 2) mosaicking and compositing, 3) reflectance calibration, 4) data

237 fusion, and 5) deriving additional metrics (see a flowchart in Supplementary Figure 1). The

238 process was repeated for each classified year (2016, 2017, and 2018), using all images available

239 from Sentinel-2, Landsat-8, and MODIS. In total, approximately 7,500 multiband images from

240 Sentinel-2, Landsat-8, and MODIS were reduced to 13 multiband images per year

241 (Supplementary Table 2).

242 Clouds and shadows were masked out from Sentinel-2 MSI and Landsat-8 OLI imagery with 243 quality flag bands. Sentinel-2 MSI was further masked by applying thresholds on VNIR and

244 SWIR bands (bands number 4, 5, 10, and 12) to detect both dense clouds and cirrus clouds ${ }^{31,32}$.

245 The cloud-free Sentinel-2 MSI, Landsat-8 OLI, and MODIS time-series were mosaicked and 246 composited independently. Before data fusion, the Landsat-8 and MODIS time-series were

247 calibrated to match the reflectance values of Sentinel-2. For that, we calculated the ratio between 248 overlapping pixels from Sentinel-2, Landsat-8, and MODIS for each monthly composite. The 249 calculated ratio was then used as a multiplication factor for each pixel in Landsat-8 and MODIS 250 composites to match with Sentinel-2 data sets. Additionally, Landsat and MODIS images were 251 resampled to $10 \mathrm{~m}$ to match the resolution of Sentinel-2. In total, we fused the three optical time- 
252 series into 13 monthly image composites_-January through December, plus January of the

253 following year. When multiple cloud-free pixels from different optical sensors were present for a

254 location and month, the pixels with the highest NDVI were prioritized. The cloud-masked

255 Sentinel-2 composites were used first, whereas Landsat and MODIS were used only to fill cloud-

256 induced gaps in the Sentinel-2 time-series. Approximately $85 \%$ of the study area was covered by

257 Sentinel-2 composite data for each period. The remaining cloud-masked area was first filled with

258 the pre-processed Landsat-8 composites and, if any cloud-masked area remained, MODIS was

259 used to fill final data gaps (see Supplementary Figure 2 and Table 3).

260 We also calculated and included NDVI, NDWI, and time-series seasonality metrics — minimum,

261 maximum, amplitude, and standard deviation — because seasonality metrics can boost

262 classification accuracies ${ }^{5,33}$. Additionally, we included the 100-m resolution Copernicus Land

263 Cover Map in the classification to help the random forest classifier classify crops in areas with a

264 high probability of crops being present (Supplementary Table 2).

265 The Sentinel-1 VV and VH time-series were processed through two steps: 1)

266 mosaicking/compositing, and 2) deriving additional metrics. The process was repeated for each

267 classified year, using all images that had been acquired within the given year. The Sentinel-1 VV

268 and $\mathrm{VH}$ annual time-series were mosaicked and composited into 12 monthly composites

269 separately for VV and VH. For the SAR imagery, compositing was achieved by condensing the

270 time-series into the average reflectance values in monthly intervals (differing from the optical

271 time-series which was composited through gap-filling), which could help to reduce speckle and

272 noise common in SAR datasets ${ }^{34,35}$. The 12-month SAR time-series was then also used to

273 calculate radar seasonality metrics (for the VV-polarization only), which were incorporated into

274 the layer stack for classification. To increase abandoned and non-abandoned crop separability, 
275 we used the Haralick technique and calculated entropy and inertia ('grey-level co-occurrence

276 matrix') texture measures for both the VV and VH monthly composites with $5 * 5$ pixels in GEE

$277{ }^{34}$. In total, we had 136 inputs/bands for each annual layer stack, which was later classified with

278 the random forest algorithm (Supplementary Table 2).

\section{Training Data for Land-cover Classification}

281 Reference data for training the random forest classifier were obtained from the United Nations

282 WFP for 2017 and 2018. Over 2,000 fields were allocated with non-differential GPS during the

283 field campaigns in 2017 and 2018, and the crop types were labeled by WFP experts

284 (Supplementary Table 4). We used the centroids from digitized fields as training samples to 285 mitigate potential error of imprecise digitizing of surveyed plots. The reference field data for 286 croplands were not collected in 2016 by WFP experts. Therefore, cropland training data were 287 instead digitized manually from multi-temporal VHR imagery available for 2016 via Google 288 Earth $^{\mathrm{TM}}$, Bing ${ }^{\mathrm{TM}}$ (e.g., 1.84-meter WorldView) and Planet Explorer ${ }^{\mathrm{TM}}$ (5-meter RapidEye and 3289 meter PlanetScope). Training data for all non-cropland land-cover classes (savanna, forest, bare, 290 grassland, water, and impervious surface combined) were assigned by visual expert 291 interpretation for all years using VHR imagery from the sources listed above.

\section{Land-cover Classification}

294 To produce land-cover classifications for 2016, 2017, and 2018, we used the non-parametric 295 machine-learning random forest classifier available in GEE. We utilized the SciKit feature 
296 selection package in Python, including precursive feature elimination and cross-validation in

297 order to run sensitivity tests for random forest parameters and feature selection based on training

298 data ${ }^{36}$. We used 10-fold cross-validation and 500 trees for the random forest. The feature

299 selection results were used to identify the top 60 performing features for each year, thus reducing

300 the layer stack's size and ensuring the utility of the best features (performance plateaued after

301 approximately 60 features). The image classifications were conducted in GEE using the top-

302 performing features. Again, the random forest classifier was parameterized with 500 trees and

303 input features were equal to the square root of the number of features. Land-cover was initially

304 classified into seven classes: cropland, savanna, forest, bare, grassland, water, and artificial

305 surface (the description of land-cover classes can be found in Supplementary Table 5).

\section{Accuracy Assessment}

308 To validate the land-cover maps, we produced an independent validation dataset of 1000 points

309 following the recommended accuracy assessment practices ${ }^{37}$. A stratified random sample design

310 was implemented to target smaller land-cover classes, thereby meeting the randomized sample

311 requirement while maintaining an acceptable standard error for our classes. We digitized 35

312 strata of $15 \times 15 \mathrm{~km}$ that targeted smaller land-cover classes (Supplementary Figure 3). We

313 sampled validation points with a minimum distance of $1 \mathrm{~km}$, which returned a Moran's I at

$314<0.40$ based on the 2017 classified map. The validation sample was labeled following visual

315 interpretation of high-resolution imagery available from Digital Globe ${ }^{\mathrm{TM}}$ and Planet ${ }^{\mathrm{TM}}$, accessed

316 through Google Earth ${ }^{\mathrm{TM}}$, Bing ${ }^{\mathrm{TM}}$, and Planet Explorer ${ }^{\mathrm{TM}}$ online platforms. Each validation point

317 was revisited and thematic land-cover classes were assigned separately for 2016, 2017, and 2018. 
318 Error-adjusted area corrections based on the accuracy assessment matrix and initial area

319 estimates would have required the sample to represent land-cover proportions of the entire study

320 area ${ }^{37}$. However, these criteria could not be met, because the crops covered only a small

321 proportion of the study area. Therefore, we calculated both the error-adjusted and unadjusted

322 area estimates (Supplementary Table 6, 7, 8).

\section{Revealing the Impacts of Armed Conflict on Cultivated Areas with Propensity Score}

\section{Matching}

326 Three covariates were selected to account for the occurrence of violent conflict: distance to

327 roads, distance to settlements, and county-level population density, which have been proven

328 relevant in explaining the spatial determinants of land-cover change, including cropland

329 abandonment ${ }^{38-40}$ and the occurrence of conflict ${ }^{6}$. The distance variables were produced based

330 on Open Street Maps road and settlement data, and the population density per county was

331 calculated based on population statistics for $2017^{41}$. The georeferenced conflict dataset was

332 obtained from the Armed Conflict Location and Event Data Project (ACLED) on political

333 violence around the globe ${ }^{42,43}$, which is one of the most comprehensive and widely used datasets

334 for quantitative conflict studies ${ }^{44,45}$. Approximately $50 \%$ of the events were recorded explicitly

335 for the settlements in which the events occurred (ACLED's category 1), whereas another $50 \%$ of

336 events were georeferenced and spatially linked to the nearest settlement (ACLED's category 2)

33746 . The dataset was limited to political violence, defined as violence that "occurs within civil

338 wars and periods of instability, public protest and regime breakdown" ${ }^{42}$. We retained only

339 conflict occurring within the study area and between the annual agricultural seasons. Therefore, 
342 'explosions/remote violence', and excluded 'protests', 'riots', and 'strategic development'

343 (Supplementary Table 9).

344 Table 4. Conflict sample periods.

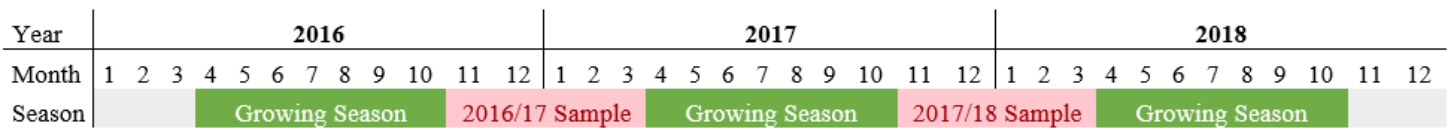

Conflict samples were generated as circles with a 5 or $10 \mathrm{~km}$ radius for each conflict point. Nonconflict samples of the same size were randomly sampled in the remaining area (Supplementary Figure 4). Sampling was performed separately in the two sample periods, 1) November 2016 to March 2017 and 2) November 2017 to Match 2018, but after extraction and linkage of the cropland extent and covariate statistics for the respective year, the samples from the two time periods were combined into one sample. The minimum sample size was chosen to account for georeferencing errors, whereas the maximum size was limited by the need to fit enough samples within the study area for propensity score matching. The entire sampling process and analysis were conducted separately for the $5 \mathrm{~km}$ and $10 \mathrm{~km}$ samples, thus providing statistics on the impact of conflict at two spatial scales.

357 with the explanatory variables to calculate propensity scores that would represent the likelihood 358 of conflict occurrence. The model was tested for goodness of fit with $\mathrm{R}^{2}$, Receiver Operating 359 Characteristic Area Under the Curve (AUC), Akaike Information Criterion (AIC), null deviance, and residual deviance ${ }^{47}$. Additionally, the model was checked for multicollinearity with variance 
361 inflation factor (VIF) and the statistical significance of covariate coefficients was assured (a

362 summary can be found in Supplementary Table 10) ${ }^{47}$. The conflict and non-conflict samples

363 were matched based on the similarity of propensity scores using the MatchIt package in R,

364 parameterized with "nearest neighbor" and restricted to the area of common support (a summary

365 can be found in Supplementary Table 11) ${ }^{48,49}$. This yielded subsamples of both the 5 and $10 \mathrm{~km}$

366 samples with a similar likelihood of the occurrence of conflict, thus reducing bias in the

367 subsequent group comparison (Supplementary Figure 4, Table 12 and 13). The comparison was

368 conducted to measure "the average effect of treatment on the treated", in this case meaning the

369 effect of conflict on the annual change in cropland extent. In addition to absolute change, change

370 was also measured and compared as a proportion of the pre-existing cropland extent.

\section{Evaluation of the Impact of Cropland Abandonment on Kilocalorie Availability}

373 We summarized abandoned lands at the county level (administrative level-3) and linked

374 abandoned areas with expected crop type proportions, yield, and kilocalorie estimates. Then, we

375 calculated the unattained kilocalories. Crop type proportions were available at the sub-national

376 level (Western Equatoria, Central Equatoria, and Lakes) circa 2018, for the major crops

377 comprising $88 \%$ of produced crops in the study area: sorghum, maize, rice, finger millet, pearl

378 millet, groundnuts, cassava, beans, and sesame ${ }^{11,21,29,50}$. Average yields (2014-2016) for cassava

379 and groundnuts were available at the province level ${ }^{29,51,52}$ (WFP/FAO, 2014-2017) and for other

380 crops at the national level ${ }^{53}$. To convert the unattained crop yields into kilocalories, we used

381 extensive nutrient profile data on various crops from the Food Data Central of the USDA

382 (Supplementary Table 13) ${ }^{16}$. We assessed how many households and people could be supported 
383 if abandonment had not occurred by using the reported average of $2180 \mathrm{kcal}$ per day per capita in

384 South Sudan ${ }^{54}$, which was slightly above the Minimum Dietary Energy Requirements (MDER)

385 of $1751 \mathrm{kcal}$ per day per capita.

386

387

388

389

390

391

392

393

394

395

396

397

398 


\section{References}

400 1. Godfray, H. C. J. et al. Food security: the challenge of feeding 9 billion people. Science $401 \quad$ (80-. ). 327, 812-818 (2010).

402 2. Foley, J. A. et al. Solutions for a cultivated planet. Nature 478, 337-342 (2011).

403 3. FAO, IFAD, UNICEF, WFP \& WHO. The State of Food Security and Nutrition in the $404 \quad$ World 2018. Building climate resilience for food security and nutrition. (2018).

405 doi:10.1093/cjres/rst006.

406

4. UN. Goal 2: Zero Hunger. https://www.un.org/sustainabledevelopment/hunger/ (2019).

407

408

409 Lett. 12, (2017).

410

6. Baumann, M. \& Kuemmerle, T. The impacts of warfare and armed conflict on land

411 systems. J. Land Use Sci. 11, 672-688 (2016).

412 7. Witmer, F. D. W. Detecting war-induced abandoned agricultural land in northeast Bosnia using multispectral, multitemporal Landsat TM imagery. Int. J. Remote Sens. 29, 3805-

414 3831 (2008).

415 8. Benayas, J. R., Martins, A., Nicolau, J. M. \& Schulz, J. J. Abandonment of agricultural land: an overview of drivers and consequences. CAB Rev. Perspect. Agric. Vet. Sci. Nutr. Nat. Resour. 2, 1-14 (2007). 
421 10. Puma, M. J. et al. A developing food crisis and potential refugee movements. Nat.

$422 \quad$ Sustain. 1, 380-382 (2018).

423 11. WFP/FAO. Special Report - Crop and Food Security Assessment Mission to South Sudan, 424 March 2018. http://www.fao.org/3/I8702EN/i8702en.pdf (2018) doi:978-92-5-130378-8.

425 12. Battersby, J. \& Watson, V. Addressing food security in African cities. Nat. Sustain. 1, $426 \quad 153-155(2018)$.

427 13. Yin, H. et al. Agricultural abandonment and re-cultivation during and after the Chechen 428 Wars in the northern Caucasus. Glob. Environ. Chang. 55, 149-159 (2019).

429 14. Somanathan, E., Prabhakar, R. \& Mehta, B. S. Decentralization for cost-effective 430 conservation. Proc. Natl. Acad. Sci. 106, 4143-4147 (2009).

431 15. Rosenbaum, P. R. \& Rubin, D. B. The Central Role of the Propensity Score in Observational Studies for Causal Effects Author ( s ): Paul R . Rosenbaum and Donald B . 433

16. U.S.D.A. FoodData Central. https://fdc.nal.usda.gov/index.html (2020).

17. Bégué, A. et al. Remote sensing and cropping practices: A review. Remote Sens. 10, 1-32 437 (2018). 
image series at high temporal and spatial resolutions. Remote Sens. 8, 1-21 (2016).

440

441

442

443

444

445

446

447

448

449

450

451

452

453

454

455

456

457

458

19. Carrasco, L., O’Neil, A. W., Daniel Morton, R. \& Rowland, C. S. Evaluating combinations of temporally aggregated Sentinel-1, Sentinel-2 and Landsat 8 for land cover mapping with Google Earth Engine. Remote Sens. 11, (2019).

20. Moreno-Martínez, Á. et al. Interpolation and gap filling of Landsat reflectance time series. Int. Geosci. Remote Sens. Symp. 2018-July, 349-352 (2018).

21. WFP/FAO. Special Report - Crop and Food Security Assessment Mission to South Sudan, March 2019. (2019).

22. Ray, D. K. et al. Climate change has likely already affected global food production. PLoS One 14, e0217148 (2019).

23. Schleussner, C.-F., Donges, J. F., Donner, R. V \& Schellnhuber, H. J. Armed-conflict risks enhanced by climate-related disasters in ethnically fractionalized countries. Proc. Natl. Acad. Sci. 113, 9216-9221 (2016).

24. Mach, K. J. et al. Climate as a risk factor for armed conflict. Nature 571, 193-197 (2019).

25. Kamp, J. Weighing up reuse of Soviet croplands. Nature 505, 483 (2014).

26. Schiermeier, Q. Soviet Union's collapse led to massive drop in carbon emissions. Nature (2019) doi:10.1038/d41586-019-02024-6.

27. Huang, X., Ziniti, B. \& Torbick, N. Assessing Conflict Driven Food Security in Rakhine, Myanmar with Multisource Imagery. Land 8, 95 (2019).

28. Chaudhary, S. et al. A Synopsis of Farmland Abandonment and Its Driving Factors in 
Nepal. Land 9, 84 (2020).

29. WFP/FAO. Special Report - Crop and Food Security Assessment Mission to South Sudan, May 2017. http://www.fao.org/3/a-i7058e.pdf (2017).

30. Gorelick, N. et al. Google Earth Engine: Planetary-scale geospatial analysis for everyone. Remote Sens. Environ. 202, 18-27 (2017).

31. Murphy, S. Cloud masking of Sentinel 2 using Google Earth Engine. (2018).

32. ESA. Technical Guide: Cloud Masks. https://sentinel.esa.int/web/sentinel/technicalguides/sentinel-2-msi/level-1c/cloud-masks (2019).

33. Phalke, A. R. \& Özdoğan, M. Large area cropland extent mapping with Landsat data and a generalized classifier. Remote Sens. Environ. 219, 180-195 (2018).

34. Inglada, J., Vincent, A., Arias, M. \& Marais-Sicre, C. Improved early crop type identification by joint use of high temporal resolution sar and optical image time series. Remote Sens. 8, (2016).

35. Van Tricht, K., Gobin, A., Gilliams, S. \& Piccard, I. Synergistic use of radar sentinel-1 and optical sentinel-2 imagery for crop mapping: A case study for Belgium. Remote Sens. 10, 1-22 (2018).

36. SciKit. sklearn.feature_selection.RFECV. https://scikitlearn.org/stable/modules/generated/sklearn.feature_selection.RFECV.html (2019).

37. Olofsson, P. et al. Good practices for estimating area and assessing accuracy of land change. Remote Sens. Environ. 148, 42-57 (2014). 
479 38. Prishchepov, A. A., Müller, D., Dubinin, M., Baumann, M. \& Radeloff, V. C.

Determinants of agricultural land abandonment in post-Soviet European Russia. Land use

481 policy 30, 873-884 (2013).

482

483

484

485

486

487

488

489

490

491

492

493

494

495

496

497

39. Wilson, S. A. \& Wilson, C. O. Modelling the impacts of civil war on land use and land cover change within Kono District, Sierra Leone: A socio-geospatial approach. Geocarto Int. 28, 476-501 (2013).

40. Sieber, A. et al. Landsat-based mapping of post-Soviet land-use change to assess the effectiveness of the Oksky and Mordovsky protected areas in European Russia. Remote Sens. Environ. 133, 38-51 (2013).

41. HDX. South Sudan - County Population Estimates - 2015-2020.

https://data.humdata.org/dataset/south-sudan-county-population-estimates-2015-2020 (2019).

42. ACLED. About ACLED. https://www.acleddata.com/about-acled/ (2019).

43. Raleigh, C., Linke, A., Hegre, H. \& Karlsen, J. Introducing ACLED: An armed conflict location and event dataset. J. Peace Res. 47, 651-660 (2010).

44. Donnay, K., Dunford, E. T., McGrath, E. C., Backer, D. \& Cunningham, D. E. Integrating Conflict Event Data. J. Conflict Resolut. 63, 1337-1364 (2019).

45. Eck, K. In data we trust? A comparison of UCDP GED and ACLED conflict events datasets. Coop. Confl. 47, 124-141 (2012).

46. Raleigh, C. \& Dowd, C. Armed Conflict Location and Event Data Project (ACLED) Codebook. (2015). 
500 47. Gellrich, M., Baur, P., Koch, B. \& Zimmermann, N. E. Agricultural land abandonment and natural forest re-growth in the Swiss mountains: A spatially explicit economic analysis. Agric. Ecosyst. Environ. 118, 93-108 (2007).

48. Ho, D. E., Imai, K., King, G. \& Stuart, E. A. MatchIt. 804, 495-2027 (2011).

49. Caliendo, M. \& Kopeinig, S. Some practical guidance for the implementation of 505 propensity score matching. J. Econ. Surv. 22, 31-72 (2008).

50. WFP/FAO. Special Report - Crop and Food Security Assessment Mission February 2016.

507 (2016).

51. WFP/FAO. Special Report - Crop and Food Security Assessment Mission to South Sudan, February 2014. (2014).

52. WFP/FAO. Special Report - Crop and Food Security Assessment Mission to South Sudan, May 2015. (2015).

512 53. FAO. Food and Agriculture Organization of the United Nations, FAOSTAT Database. Trade. Crops and Livestock Products. http://faostat3.fao.org/browse/T/TP/E (2020).

514 54. SIFSIA. Food and Nutrition Security Assessment in Sudan: Analysis of 2009 National 515 Baseline Household Survey. Khartoum, Sudan: Sudan Integrated Food Security Iinformation For Action. http://www.fao.org/resilience/resources/resourcesdetail/ru/c/170310/ (2010). 
Figures
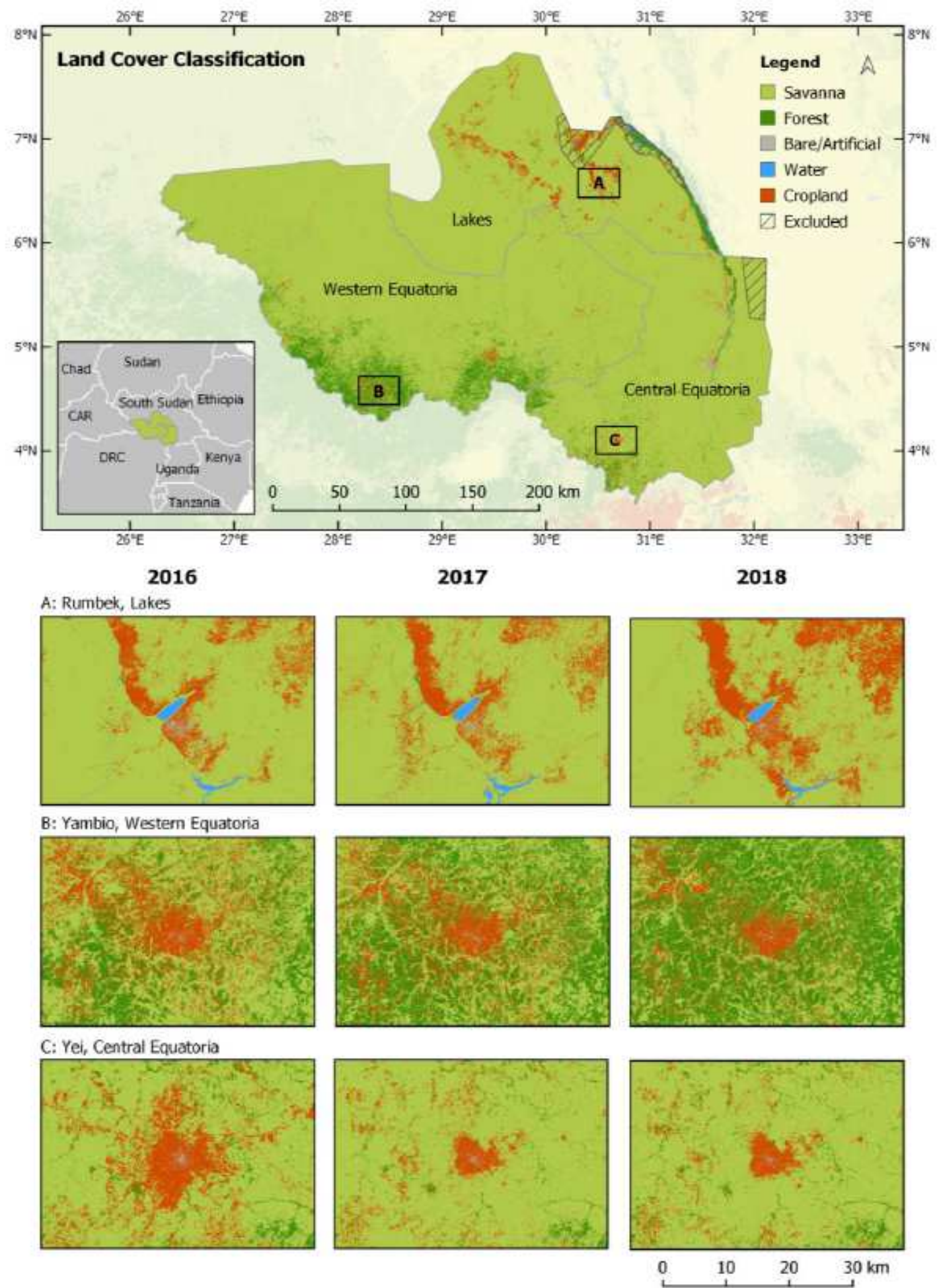

\section{Figure 1}

Land-cover map for 2018 produced with supervised image classification and the examples of land-cover changes in three agricultural areas-Rumbek, Yambio, and Yei (A, B, and C, respectively). Note: The designations employed and the presentation of the material on this map do not imply the expression of 
any opinion whatsoever on the part of Research Square concerning the legal status of any country, territory, city or area or of its authorities, or concerning the delimitation of its frontiers or boundaries. This map has been provided by the authors.

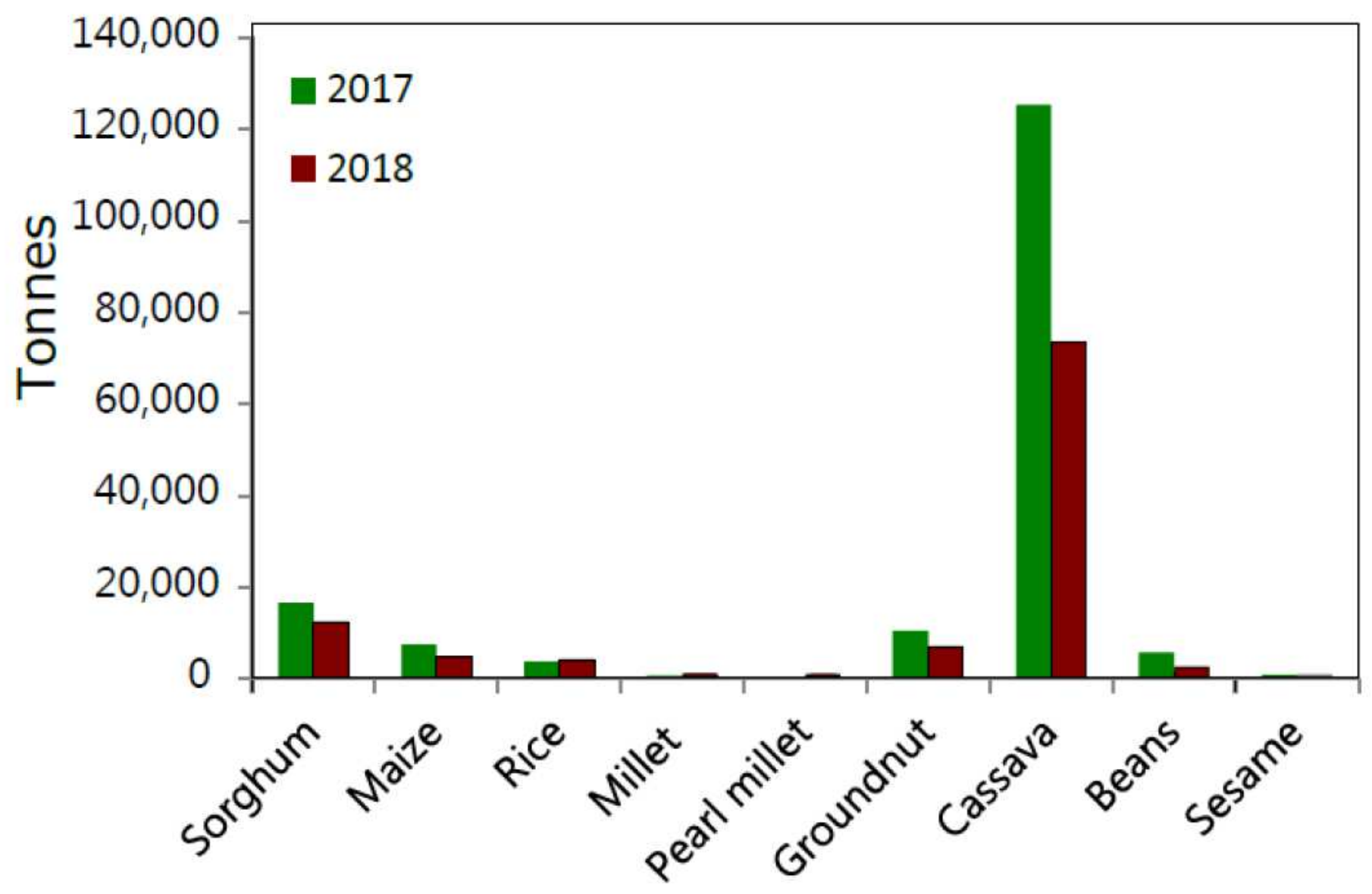

Figure 2

Missed crop production due to cropland abandonment.

\section{Supplementary Files}

This is a list of supplementary files associated with this preprint. Click to download.

- Supplementaryinformation.pdf 